Case study

\title{
Asymmetric midshaft femur remodeling in an adult male with left sided hip joint ankylosis, Metal Period Nagsabaran, Philippines
}

Justyna J. Miszkiewicz ${ }^{1 *}$, Claire Rider ${ }^{1}$, Shimona Kealy ${ }^{2,3}$, Christina Vrahnas ${ }^{4,5,6}$, Natalie A. Sims $^{4,5}$, Jitraporn Vongsvivut ${ }^{7}$, Mark J. Tobin ${ }^{7}$, Mary Jane Louise A. Bolunia ${ }^{8}$, Alexandra S. De Leon ${ }^{8}$, Antonio L. Peñalosa ${ }^{8}$, Pablo S. Pagulayan ${ }^{8}$, Adan V. Soriano ${ }^{8}$, Ruth Page ${ }^{1}$, Marc F. Oxenham ${ }^{1,9}$

${ }^{1}$ School of Archaeology and Anthropology, Australian National University, 44 Linnaeus Way, 2601 Canberra, ACT, Australia

${ }^{2}$ School of Culture, History, and Language, Archaeology and Natural History, College of Asia and the Pacific, Australian National University, 0200 Canberra, ACT, Australia

${ }^{3}$ ARC Centre of Excellence for Australian Biodiversity and Heritage, Australian National University, 0200 Canberra, ACT, Australia

${ }^{4}$ Bone Biology and Disease Unit, St. Vincent's Institute of Medical Research, 9 Princes Street, Fitzroy, Melbourne, VIC, 3065, Australia

${ }^{5}$ Department of Medicine, The University of Melbourne, St. Vincent's Hospital, Melbourne, VIC, 3065, Australia

${ }^{6} \mathrm{MRC}$ Protein Phosphorylation and Ubiquitylation Unit, James Black Centre, University of Dundee, Dundee, DD1 4HN, United Kingdom

${ }^{7}$ Infrared Microspectroscopy (IRM) Beamline, ANSTO - Australian Synchrotron, 800 Blackburn Road, 3168 Clayton, VIC 3168, Australia

${ }^{8}$ Archaeology Division, National Museum of the Philippines, P. Burgos St., Manila 1000, Philippines

${ }^{9}$ Department of Archaeology, University of Aberdeen St. Mary's, Elphinstone Road Aberdeen AB24 3UF, Scotland, United Kingdom

\section{*Corresponding author:}

Justyna J. Miszkiewicz

Justyna.Miszkiewicz@anu.edu.au

School of Archaeology and Anthropology

44 Linnaeus Way

Australian National University

2601 Canberra

Australian Capital Territory

Australia 


\begin{abstract}
Objective: This study investigated microstructural changes of the right and left midshaft femur in an archaeological individual afflicted with left-sided hip joint ankylosis to assess whether increased cortical porosity was present as a result of leg disuse.

Materials: The individual is a middle-aged adult male excavated from the Metal Period ( 2000 BP) Nagsabaran, Luzon Island, Philippines.

Methods: Following standard examination of femur gross anatomy and differential diagnosis of the hip joint fusion, $\sim 1 \mathrm{~cm}$ thick posterior midshaft femur sampled were removed for microstructural examination. Using static histomorphometry, bone multi-cellular unit activity from Haversian canal (vascular pore) density, area, and circularity was reconstructed. Spatial positioning of Haversian canals was mapped using Geographic Information Systems (GIS) software. Phosphate, carbonate, and carbonate:phosphate ratios were obtained using synchrotron-sourced Fourier transform infrared (sFTIRM) microspectroscopy.
\end{abstract}

Results The left femur had greater cortical pore density, with smaller and rounder vascular canals, in addition to lower matrix levels of phosphate and carbonate, when compared to the right femur.

Conclusions Our data indicate compromised bone tissue in the left femur, and conform to expected bone functional adaptation paradigms of remodeling responses to pathological and biomechanical changes.

Significance The preservation of this individual's hip abnormality created a unique opportunity to evaluate intra-skeletal bone health asymmetry, which may help other researchers evaluate the presence of limb disuse in archaeological samples.

Limitations A lack of lower limb data limits our interpretations to femur remodeling only.

Suggestions for Further Research Future research efforts should aim to examine the presence of remodeling changes in all bones of the lower limb.

Keywords: joint stiffness; histology; carbonate; phosphate 


\section{INTRODUCTION}

Paleopathological cases of diagnosable paralysis or one-sided immobilization are rare. A few noteworthy reports include child-onset paralysis in a young adult male from Neolithic Vietnam (Oxenham et al., 2009); acute poliomyelitis-induced lower leg bone loss in a middle-aged male from early Medieval Poland (Kozłowski and Piontek, 2000); and neurogenic paralysis in a male and female from Medieval Croatia (Novak et al., 2014). Microscopic studies have indicated that child-onset and adult-acquired limb structure abnormalities have different bone manifestations (Lazaneby and Pfeiffer, 1993; Kozłowski and Piontek, 2000; Walker et al., 2019). A preliminary histological intra-skeletal analysis of child-onset paralysis in a young adult male from Neolithic Vietnam revealed cessation of bone remodeling and retention of primary bone, contained within abnormally under-developed leg bones (Walker et al., 2019). Alternatively, bone tissue impacted by adult-acquired leg disuse displays increased remodeling of secondary bone. A case study of a $19^{\text {th }}$ century 25 -year-old young male below-knee amputee, who had worn a left lower leg prosthesis, reported that the amputation significantly affected his bone remodeling (Lazenby and Pfeiffer, 1993). Histological samples removed from the left and right midshaft femur revealed endocortical expansion, and intra-cortical Haversian remodeling in the left femur compared to bone tissue of a 68-year-old (Lazenby and Pfeiffer, 1993).

Lower limb bone loss that results from immobilization is associated with an absent or significantly reduced mechanical stimulus. Kozłowski and Piontek’s (2000:14) examination of an under-developed right leg in an early Medieval Polish male noted thinner trabeculae and reduced osteocyte lacunae density in metatarsal bone, citing "dysfunction atrophy" as an underlying cause of bone loss. Bone loss is well documented in human cases of limb paralysis and space travel (e.g. Giangregorio and Blimkie, 2002; Eser et al., 2004; Schlecht et al., 2012; Sibonga, 2013), and animal models subjected to experimental limb immobilization (e.g. 
Uhthoff and Jaworski, 1978; Young et al., 1986; Laib et al., 2000). Bone tissue associated with limb under-use or disuse accelerated deterioration as osteoclast-mediated bone resorption predominates bone formation by osteoblasts (Alexandre and Vico, 2011). Indeed, "disuse osteoporosis" is used to describe negative effects of bed-rest or weightlessness that ultimately lead to bone loss and reduced strength (Minaire et al., 1974; Alexandre and Vico, 2011; Bartl and Bartl, 2017). Classic bone functional adaptation predictions, based on models outlined in the Utah Paradigm of Skeletal Physiology (Frost, 1987; 2000; 2003), project that abnormally low levels of mechanical strain increase bone disuse remodeling through prolonged osteoclast activity (Robling et al., 2006) (see Supplement 1).

In this study, microscopic techniques (Crowder and Stout, 2011; Miszkiewicz and Mahoney, 2016) are used to compare indicators of cortical bone remodeling and matrix composition of the left and right femur in a ca. 2000-year-old adult male from Nagsabaran, Philippines (Oxenham et al., 2015). The individual was uncovered with evidence of a long-term hip joint fusion, which likely led to disuse of his left leg. The preservation of this individual's hip abnormality created a unique opportunity to evaluate intra-skeletal bone health asymmetry, which may help other researchers evaluate the presence of limb disuse in archaeological samples.

\section{MATERIALS AND METHODS}

The individual NAG-2009-T14 B4 presenting with a left ankylosed hip joint (Figure 1) was exhumed by a team from the National Museum of the Philippines and Australian National University during 2009 excavations of Nagsabaran, Philippines (Hung et al., 2011; Oxenham et al., 2015). The remains of the individual included cranial and post-cranial elements, oriented east in an extended position. The extended supine type of burial was associated with no grave goods, but was located near a dog burial (Oxenham et al., 2015). The biological profile of the 
individual was previously independently constructed by two co-authors of our study (Paige, 2015; Rider, 2017). The application of standard physical anthropology methods of age-at-death and sex estimation (Buikstra and Ubelaker, 1994) resulted in the assignment of biological male sex and middle-aged category of age-at-death (35-50 years old). Stature estimation results using methods appropriate for fibula and radius (based on Thai standards, Pureepatpong et al., 2012, Oxenham et al., 2015) yielded a range of $155.5-161.7 \mathrm{~cm}$. The individual's dental metric data, previously used to estimate his ancestral affinities, were concluded to be similar to modern Bunun Aboriginals from Taiwan (Oxenham et al., 2015).

\subsection{Archaeological context}

Nagsabaran is located $\sim 22 \mathrm{~km}$ upstream from the mouth of the Cagayan River on the north coast of Luzon, Cagayan province (Piper et al., 2009; Hung et al., 2011; Oxenham et al., 2015). It is 4.2 hectares large, 600 metres long, 100 metres wide, and reaches a maximum depth of three metres (Page, 2015). The site dates from the Neolithic to Metal Period, and is composed of more than 30 shell midden sites (Church, 2012). Previously reported evidence for domesticated pigs (Amano et al., 2013) suggests that the Neolithic groups of the northern Philippines connected with Taiwan at least 4000 cal BP (Piper et al., 2009). The site is known for the funerary practice of cranial removal before deposition within a burial, which likely arose during the Neolithic (Oxenham et al., 2015). Around 2500 years ago, the end of the Neolithic period was marked by evidence of iron, bronze, and exotic stone objects. This suggests an exchange with societies of mainland and Island Southeast Asia (Bacus, 2004). Pottery, evidence for farming practices, and other linguistic data suggest the emergence of the Metal Period at 2000 BP (Bellwood and Oxenham 2008; Bellwood, 2017). The individual's burial was directly dated to $1972-1742$ BP (Oxenham et al., 2015).

\subsection{Gross anatomical analysis}


Both femora were examined macroscopically by two co-authors (CR, JJM) to collect standard morphometric data (Table 1; Buikstra and Ubelaker, 1994; Lazenby and Pfeiffer, 1993); and assess the development of muscle attachment and insertion sites of gluteus maximus, adductor magnus, vastus intermedius, vastus lateralis, adductor brevis, adductor longus, and linea aspera. The morphometric data were recorded using Work Zone ${ }^{\circledR}$ digital sliding callipers, a Paleo-Tech Concepts ${ }^{\circledR}$ laboratory osteometric board, and a measuring tape. Intra-observer error was minimized by taking the measurements two weeks apart, comparing results descriptively and averaging them. Inter-observer error was minimized by averaging initial data and data replicated by another co-author several months later. The individual's hip joint ankylosis has been previously examined macroscopically and radiographically as part of a detailed differential diagnosis (Oxenham et al., 2015).

\subsection{Microscopic analysis}

Static histomorphometry, Geographic Information Systems (GIS), and sFTIRM methods were used to collect bone metabolism and composition data. All three methods were applied to an approximately $1-\mathrm{cm}$ thick cortical quarter of each posterior midshaft femur, extracted using a Dremel tool with a rotary blade (Miszkiewicz and Mahoney, 2019; Figure 2A). Applying several methods to one sample ensured that a minimal amount of bone was destroyed, following ethical codes of conduct and practice within palaeopathology when using invasive techniques (Mays et al., 2015). Samples for histology and sFTIRM were prepared following standard methods applicable to archaeological human bone and embedded in epoxy resin, ground, polished and cover-slipped (Miszkiewicz and Mahoney, 2017).

First, four thin sections were prepared (two per femur) and examined by two co-authors (JJM, CR). Data presented here are from two best quality sections. Using Image ${ }^{\circledR}$ (v. 1.52), data were collected representative of Haversian canals (cortical pores) by estimating their density 
(H.Dn), Haversian canal area (H.Ar) (Miszkiewicz and Mahoney, 2019), circularity (H.Cr) (Maggio and Franklin, 2019), and the inverse of AR ratio (H.AspR ${ }^{-1}$ ) (Hennig et al., 2015). We report raw H.Ar data, as well as data adjusted by the sampled area, to avoid possible isometry of section size and Haversian area (Miszkiewicz and Mahoney, 2019).

Second, the histology images in a .TIFF format (one image per femur), with pre-marked Haversian canals, were analysed in the software package ArcGIS 10.5.1 (ESRI, 2017) to map spatial distribution of cortical pores, and measure distances between neighboring canals (Rose et al., 2012) (Figure 2C). We used Point and Kernel densities to understand high-low spatial organization of canals, and the Average Nearest Neighbour Distance method to estimate linear cortical space (in $\mu \mathrm{m}$ ) between canals (Okabe et al., 2009). We interpret absolute average data on canal-canal relationships in $360^{\circ}$, which includes distances to the nearest neighbor, second nearest, and third nearest neighbors. Nearest neighbor data was collected to indicate the proximity of the first closest Haversian canal. Due to canal re-marking in ArcGIS, an insignificant reduction in canal number counted from the histology images occurred (two fewer canals in the left femur, and three fewer canals in the right femur).

Third, sFTIRM technique was used to evaluate bone phosphate and carbonate levels (Heaney et al., 2010; Bertrand et al., 2012). The samples were analysed at the Australian Synchrotron using the Infrared Microspectroscopy beamline (Clayton, Victoria), following methods reported by Vrahnas et al. (e.g. 2016) and modified for application in our study by use of a custom-built attenuated total reflectance accessory placed in direct contact with the surface of the bone sample (Vongsvivut et al., 2019). We collected high signal-to-noise sFTIRM spectra from a total of eight regions of interest (ROIs) located on the endocortical and sub-periosteal regions of each sample (Figure 2D). The measurements were collected using a Bruker V80v FTIR spectrometer coupled with a Hyperion 3000 IR microscope. The spectral components of interest were two bands of carbonates $v_{2}\left(890-850 \mathrm{~cm}^{-1}\right)$ and $v_{3}\left(1500-1400 \mathrm{~cm}^{-1}\right)$, and 
phosphate (mineral) (1180-916 $\left.\mathrm{cm}^{-1}\right)$, from which carbonate $\left(v_{2}\right)$ :mineral ratios $\left(890-850 \mathrm{~cm}^{-}\right.$

${ }^{1}: 1180-916 \mathrm{~cm}^{-1}$ ) were computed (Rey et al., 1989; Ou-Yang et al., 2001; Madupalli et al., 2017). Using OPUS 7.2 software suite (Bruker Optik GmbH, Germany), integration files were created and applied to extract peak height (in absorbance unit) and area under the trace. Data are reported for a minimum 2,605 and maximum 5,170 spectra in the left, and 3,893 minimum and 5,128 maximum spectra in the right femur.

\section{RESULTS}

\subsection{Left and right femur differences and differential diagnosis}

The true length of the left femur was impossible to estimate due to the fusion of the femoral head to the acetabulum (Figure 1B). The fusion also led to a lateral rotation of the left femoral shaft, whereby the linea aspera region, usually located on the midline of the posterior aspect, shifted laterally. The entheseal sites were smoother and less developed in the left femur than in the right. The series of gross anatomical measurements were inconsistently different when compared between the two bones (Table 1).

The fusion in the hip joint presented with 'solid' and well remodeled lamellar bone, suggesting its presence for a relatively long period of time rather than occurring immediately (e.g. no evidence of woven bone) prior to death (see radiograph in Oxenham et al., 2015: 346). We can describe this abnormality as ankylosis; joint stiffness due to abnormal adhesion and rigidity of the connected bones (Paja, 2013). Aetiologies of ankylosed joints are multifactorial, including injury/trauma, disease/ infection, erosive arthopathies, and congenital abnormalities (Rogers and Waldron, 1995; Resnick and Kransdorf, 2004; Kacki et al., 2013). As this individual does not display lesions associated with infection (such as periosteal reaction) or congenital disorders (such as gross morphological changes to the os coxae), the most likely diagnosis is 
an injury to the left femoral neck or head (see Oxenham et al., 2015), resulting in the mobility of the individual being impacted prior to death.

\subsection{Bone microstructure differences}

Histological indicators of bone remodeling differed between the two femur samples (Table 2, Figure 3). The GIS analysis indicated that Haversian canals in the left sample clustered in closer proximities, having shorter average distances $(160.582 \mu \mathrm{m}, \mathrm{SD}=58.052)$ between the neighboring canals when compared to the right leg $(200.089 \mu \mathrm{m}$, SD $=61.839)$. Histomorphometry revealed that the area of canals was on average slightly smaller in the left sample $\left(1,906.401 \mu \mathrm{m}^{2}, \mathrm{SD}=2,104.771\right)$, and the density of vessels was higher $\left(25.25 / \mathrm{mm}^{2}\right)$, than in the right femur $\left(\mathrm{H} . \mathrm{Ar}=2,567.975 \mu \mathrm{m}^{2}, \mathrm{SD}=2,564.642 ; \mathrm{H} \cdot \mathrm{Dn}=17.36 / \mathrm{mm}^{2}\right)$. Haversian canal area data, adjusted by the examined section area, followed this trend. The circularity of canal area was marginally rounder in the left leg $(\mathrm{H} . \mathrm{Cr}=0.882)$ than in the right $(\mathrm{H} . \mathrm{Cr}=0.872)$. However, the difference in $\mathrm{H}_{\mathrm{AspR}} \mathrm{A}^{-1}$ values was more pronounced (left: 0.720 , right $=0.692$ ). The S-FTIR spectral data indicative of phosphate, carbonate $\left(v_{3}, v_{2}\right)$, and carbonate:phosphate ratios were all lower in the left sample (Figures 4,5 ). The average phosphate peak height in the left femur was 0.422 , and 0.441 in the right. The area under the trace was marginally different, with 30.416 and 30.660 in the left and the right samples respectively. Carbonate data were more variable. While the carbonate peak $v_{2}$ was comparable between the left (peak height: 0.019, area: 0.344) and the right (peak height: 0.026, area: 0.439), carbonate $v_{3}$ was substantially larger in the right sample (0.778) when compared to the left $(0.554)$. On average, $v_{3}$ peaked at 0.017 and 0.013 respectively. Carbonate:phosphate ratios were lower in the left sample (0.016) when compared to the right (0.017).

\section{DISCUSSION}


This study provides a glimpse into bone metabolic activity in an archaeological individual whose life was impacted by a hip pathology. The differential diagnosis of the left hip joint fusion discounted infectious and congenital disease as underlying aetiologies due to the individual not showing skeletal lesions such as woven bone, severe joint destruction, or underdeveloped bone macro-anatomy (Oxenham et al., 2015).

Although the histological markers of Haversian canal densities in the left femur differ from the right femur, these data still fall within similar ranges. Had the left femur been immobilized over a period of several decades, no doubt more extensive microstructural changes would have occurred. Therefore, it is likely that the left femur shows extended cortical porous space as a result of increased bone remodeling that occurred shortly after leg disuse. Haversian canals may have branched out as part of the initial bone response, which is noted by higher canal densities, smaller average area, and shorter neighboring canal distances in the left femur when compared to the right. This inference is reasonable considering that clinical literature based on individuals suffering from long-term paralysis report inverse findings to ours (Schlecht et al., 2012). Schlecht et al (2012) examined bone samples from two individuals afflicted by paralysis for approximately 26 and 50 years, respectively. In both cases, cortical bone from immobilized legs showed abnormally enlarged and lower densities of secondary osteons. Thus, it appears that long-term lack of mechanical loading associated with leg disuse eventually leads to prolonged bone resorption, as secondary osteons are not strain-repressed. It is possible that the left sample in our study shows the effect of disuse remodeling, favoring resorption over longer periods of time. There are at least three localized abnormally large pores seen in the left section (Figure 2B), and there is increased clustering of pores when viewed through Point and Kernel GIS densities (Figure 2C). This phenomenon, whereby neighboring pores prominently coalesce into "giant pores" (Chen and Kubo, 2014: 491), often occurs in osteoporotic bone, and older females (e.g. Bousson et al., 2001), deteriorating its micro-architectural integrity to the point 
of cortex trabecularization. As remodeling activity becomes erased over time, lower densities of secondary osteons become apparent (Schlecht et al. (2012). We acknowledge that our study sampled only the posterior femur cortex, whereas Schlecht et al. (2012) collected data from all the major long bones of the upper and lower limb. These sampling differences may underlie dissimilarities in our data.

Our results point to denser bone in the right femur when compared to the left, which might have provided increased support for mobility. Carbonate and mineral were also lower in the left femur, as deduced from carbonate:phosphate ratios (see Supplement 1), suggesting the bone quality was compromised. As mineral loss increases bone fragility, it compromises bone strength and may lead to fractures (Vidal et al., 2019). One alternative interpretation of our data is that experiences of limited mobility might have stimulated some loading-induced remodeling in the left leg. This would explain differences between results of this study and those where limb paralysis were reported (e.g. Schlecht et al., 2012). The combination of higher cortical porosity and lower mineralization in the left sample may be a result of elevated but localized mechanical strain resulting in an increase of smaller Haversian canals that would facilitate targeted remodeling of micro-cracks (Lee et al., 2002). Delayed bone remodeling as limb mobility improves with joint fusion cannot be excluded. A second alternative interpretation is that the left femur may have more regions of recently deposited younger bone, in which case the carbonate:phosphate ratio would also be lower (McCreadie et al., 2006; Vrahnas et al., 2016).

There are extremely few comparative examples of sFTIRM analyses of archaeological bone (Bertrand et al., 2012). However, our carbonate data appear to reflect values reported for a 5000-year-old possibly bovine (unconfirmed species identification) non-pathological cortical bone sample from Neolithic Chalain Lake in France (Reiche et al., 2010). In Reiche et al.'s (2010) study, where this sample was compared to a healthy modern reference sample, the 
reported mean carbonate contents were 0.480 and 0.430 , respectively. This is similar to our $v_{2}$ mean of 0.439 in the right femur, hinting that the low $v_{2}$ value of 0.344 in the left femur may be abnormal.

Palaeopathological literature has reported very few cases of limb immobilization (e.g. Oxenham et al., 2009; Kozłowski and Piontek, 2000; Novak et al., 2014), almost all of which are restricted to gross anatomical observations; with even fewer cases evaluating microscopic structures (e.g. Lazenby and Pfeiffer, 1993; Kozłowski and Piontek, 2000). Replicating our methods within paleopathology to recognize stages of bone deterioration can assist in identifying bone processes that occur over several decades or closer to the time of death. This, we assert, has the potential to greatly inform models of care (Oxenham et al., 2009; Tilley and Oxenham 2011).

\section{CONCLUSIONS}

This study compared the microstructure of cortical midshaft bone in the left and right femur from an archaeological individual afflicted with left hip joint ankylosis. Using a series of methods that assessed multi-hierarchical levels of bone, we report the left (afflicted) sample is characterized by increased density of cortical pores combined with lower carbonate and phosphate content. While we note this asymmetry, we also emphasise that it is not extreme. This suggests a relatively short duration of the hip abnormality impacting this individual's femoral response. The preservation of this individual's hip abnormality created a unique opportunity to evaluate intra-skeletal bone health asymmetry, which may help other researchers evaluate the presence of limb disuse in archaeological samples.

\section{ACKNOWLEDGMENTS}

This study is a result of a long-term collaboration between the National Museum of the Philippines and the Australian National University (ANU). Funding for this study was received 
from the Australian Research Council (DE190100068) and ANU CASS (microscopy equipment). ANU RSHA 2017 travel grant facilitated stay on-site at the ANSTO - Australian Synchrotron facility (Clayton, Victoria). The sFTIRM data were collected using the Infrared Microspectroscopy beamline at the Australian Synchrotron, part of ANSTO. Pau Basilia (Griffith University) assisted with English-Filipino translation of abstract. David McGregor offered continuous technical assistance on the project. We are indebted to Editor-in-Chief Anne L. Grauer for invaluable contributions to the presentation of this article; and thank Associate Editor, and two reviewers for constructive feedback on the study.

\section{FIGURE CAPTIONS}

Figure 1. (A) Individual NAG-2009-T14 B4 in situ at the archaeological site of Nagsabaran, Philippines. (B) The right (R) and left (L) femur shown from the anterior and posterior aspects. The left femur fused to the left acetabulum can be seen impacting the positioning and orientation of the left leg. The fusion of the hip joint is characterized by dense and well remodeled lamellar bone obscuring the joint line between the femoral head and acetabular margins.

Figure 2. Methods used in the study: (A) the posterior femur sampling location; (B) histology images of the sections with blue dots indicating Haversian canals, and red rectangles indicating regions of interest from which Haversian canals were measured; (C) heat maps of Haversian canal spatial distribution created using Geographic Information Systems, with red indicating higher densities and blue lower densities of canals; (D) regions of interest targeted for the measurement of carbonate and phosphate using synchrotron-sourced Fourier-transform infrared microspectroscopy.

Figure 3. Results of histological analyses: (A-C) using histomorphometry and (D) Geographic Information Systems (GIS). Haversian canal density (A: raw, B: adjusted by section area), 
circularity (white box plot) and inverse of aspect ratio (grey box plot); (C) shows increased values in the right femur. (D) shows larger distances between neighboring canals in the right femur.

Figure 4. (A) Phosphate; (B, C) carbonate and carbonate; (D) phosphate ratio displaying results of average spectrum peak height and area under the trace in the left and right femur. In all instances, the right femur shows increased values (red dashed line). (E) Example of phosphate variation in one bone region of interest illustrating the highest (pink) and lowest (blue) data.

Figure 5. Sample averaged spectra from the region of interest on the endocortical bone surface of the left and right midshaft femur, showing higher phosphate and carbonate in the right femur.

\section{REFERENCES CITED}

Alexandre, C., Vico, L., 2011. Pathophysiology of bone loss in disuse osteoporosis. Joint Bone Spine, 78, 572-576. https://doi: 10.1016/j.jbspin.2011.04.007

Amano, N., Piper, P.J., Hung, H.C., Bellwood, P., 2013. Introduced domestic animals in the neolithic and metal age of the Philippines: evidence from Nagsabaran, Northern Luzon. J. Island Coast. Archaeol. 8, 317-335. https://doi.org/10.1080/15564894.2013.781084

Bacus, E., 2004.The archaeology of the Philippine archipelago. In: Glover, I., Bellwood, P. (Eds.), Southeast Asia: From Prehistory to History. Routledge, New York, pp. 257281.

Bartl, R., Bartl, C., 2017. Immobilisation osteoporosis (disuse osteoporosis, disuse atrophy). In: Bartl R, Bartl, C. (Eds.), Bone Disorders: Biology, Diagnosis, Prevention, Therapy. Springer, Cham, pp. 287-289. https://doi.org/10.1007/978-3-319-29182-6_43

Bellwood, P., 2017. First Islanders: Prehistory and Human Migration in Island Southeast Asia. Wiley Blackwell, Hoboken, NJ. 
Bellwood, P., Oxenham, M., 2008. The expansions of farming societies and the role of the Neolithic demographic transition. In: Bocquet-Appel, J-P, Bar-Yosef, O (Eds.), The Neolithic Demographic Transition and its Consequences. Springer, Dordrecht, pp. 1334.

Bertrand, L., Cotte, M., Stampanoni, M., Thoury, M., Marone, F., Schöder, S., 2012. Development and trends in synchrotron studies of ancient and historical materials. Phys. Rep. 519, 51-96. https://doi.org/10.1016/j.physrep.2012.03.003

Bousson, V., Meunier, A., Bergot, C., Vicaut, É., Rocha, M.A., Morais, M.H., Laval-Jeantet, A.M., Laredo, J.D., 2001. Distribution of intracortical porosity in human midfemoral cortex by age and gender. J. Bone Miner. Res. 16(7), 1308-1317. https://doi.org/10.1359/jbmr.2001.16.7.1308

Buikstra, J.E., Ubelaker, D.H., 1994. Standards for Data Collection from Human Skeletal Remains. Arkansas Archaeological Society Research Series No. 44. Arkansas Archaeological Society, Fayetteville.

Church, E., 2012, Childhood Health at Iron Age Nagsabaran: A Study of the Prevalence, Chronology and Duration of Linear Enamel Hypoplasia. Honours Thesis, Australian National University, Canberra, Australia.

Crowder, C., Stout, S., 2011. Bone Histology: An Anthropological Perspective. CRC Press, Boca Raton, FL.

Eser, P., Frotzler, A., Zehnder, Y., Wick, L., Knecht, H., Denoth, J., Schiessl, H., 2004. Relationship between the duration of paralysis and bone structure: a pQCT study of spinal cord injured individuals. Bone 34, 869-880. https://doi.org/10.1016/j.bone.2004.01.001 
ESRI, 2017. ArcGIS 10.5.1 for Desktop. Environmental Systems Research Institute, Redlands, California, USA.

Frost, H. M., 1987. Bone "mass" and the "mechanostat": a proposal. Anat. Rec. 219, 1-9. https://doi: 10.1002/ar.1092190104

Frost, H. M., 2000. The Utah paradigm of skeletal physiology: an overview of its insights for bone, cartilage and collagenous tissue organs. J. Bone Miner. Res. 18, 305-316. https://doi: 10.1007/s007740070001

Frost, H. M., 2003. Bone's mechanostat: a 2003 update. Anat. Rec. 275, 1081-1101. https://doi: 10.1002/ar.a.10119

Giangregorio, L., Blimkie, C. J., 2002. Skeletal adaptations to alterations in weight-bearing activity. Sports Med. 32, 459-476. https://doi.org/10.2165/00007256-20023207000005

Heaney, R. P., Recker, R. R., Watson, P., Lappe, J. M., 2010. Phosphate and carbonate salts of calcium support robust bone building in osteoporosis. Am. J. Clin. Nutr. 92, 101-105. https://doi.org/10.3945/ajen.2009.29085

Hennig, C., Thomas, C. D. L., Clement, J. G., Cooper, D. M., 2015. Does 3D orientation account for variation in osteon morphology assessed by 2D histology?. J. Anat. 227, 497-505. https:// doi.org/10.1111/joa.12357

Hung, H-c., Carson, M.T., Bellwood, P., Campos, F.Z., Piper, P.J., Dizon, E., Bolunia, M.J.L.A., Oxenham, M., Chi, Z., 2011. The first settlement of Remote Oceania: the Philippines to the Marianas. Antiquity 85, 909-926. https://doi.org/10.1017/S0003598X00068393 
Jaworski, Z. F., Liskova-Kiar, M., Uhthoff, H. K., 1980. Effect of long-term immobilisation on the pattern of bone loss in older dogs. J. Bone Jt. Surg. 62, 104-110.

Kacki, S., Castex, D., Blanchard, P., Bessou, M., Giuliani, R., Dutour, O., 2013. Differential diagnosis of carpal and tarsal ankylosis on dry bones: example from the catacomb of Saints Peter and Marcellinus (Rome, 1st-3rd century AD). Int. J. Paleopathol. 3, 274281. https://doi.org/10.1016/j.ijpp.2013.07.002

Kozłowski, T., Piontek, J., 2000. A case of atrophy of bones of the right lower limb of a skeleton from a medieval (12th-14th centuries) burial ground in Gruczno, Poland. J. Paleopath 12, 5-16.

Laib, A., Barou, O., Vico, L., Lafage-Proust, M. H., Alexandre, C., Rügsegger, P., 2000. 3D micro-computed tomography of trabecular and cortical bone architecture with application to a rat model of immobilisation osteoporosis. Med. Biol. Eng. Comput. 38, 326-332. https://doi.org/10.1007/BF02347054

Lazenby, R. A., Pfeiffer, S. K., 1993. Effects of a nineteenth century below-knee amputation and prosthesis on femoral morphology. Int. J. Osteoarch. 3, 19-28. https://doi.org/10.1002/oa.1390030103

Lee, T.C., Staines, A., Taylor, D., 2002. Bone adaptation to load: microdamage as a stimulus for bone remodelling. J. Anat. 201(6), 437-446. https://doi.org/10.1046/j.14697580.2002.00123.x

Madupalli, H., Pavan, B., Tecklenburg, M.M., 2017. Carbonate substitution in the mineral component of bone: Discriminating the structural changes, simultaneously imposed by carbonate in A and B sites of apatite. J. Solid State Chem. 255, 27-35. https://doi.org/10.1016/j.jssc.2017.07.025 
Maggio, A., Franklin, D., 2019. Histomorphometric age estimation from the femoral cortex: A test of three methods in an Australian population. Forensic Sci. Int. 303, 109950. https://doi.org/10.1016/j.forsciint.2019.109950

Mays, S., Elders, J., Humphrey, L., White, W., Marshall, P., 2013. Science and the Dead: A Guideline for the Destructive Sampling of Archaeological Human Remains for Scientific Analysis. English Heritage Publishing with the Advisory Panel on the Archaeology of Burials in England.

McCreadie, B. R., Morris, M. D., Chen, T. C., Rao, D. S., Finney, W. F., Widjaja, E., Goldstein, S. A., 2006. Bone tissue compositional differences in women with and without osteoporotic fracture. Bone, 39, 1190-1195. https://doi.org/10.1016/j.bone.2006.06.008

Minaire, P., Meunier, P., Edouard, C., Bernard, J., Courpron, P., Bourret, J., 1974. Quantitative histological data on disuse osteoporosis. Calcif. Tiss. Res. 17 57-73. https://doi: $10.1007 / \mathrm{bf} 02547214$

Miszkiewicz, J. J., Mahoney, P., 2016. Ancient human bone microstructure in medieval England: comparisons between two socio-economic groups. Anat. Rec. 299, 42-59. https://doi.org/10.1002/ar.23285

Miszkiewicz, J. J., Mahoney, P., 2017. Human bone and dental histology in an archaeological context. In: Thompson, T., Errickson, D. (Eds), Human Remains: Another Dimension. The Application of Imaging to the Study of Human Remains. Elsevier Academic Press, pp. 29-43.

Miszkiewicz, J. J., Mahoney, P., 2019. Histomorphometry and cortical robusticity of the adult human femur. J. Bone Miner. Metab. 37(1), 90-104. https://doi: 10.1007/s00774-0170899-3. 
Novak, M., Čavka, M., Šlaus, M., 2014. Two cases of neurogenic paralysis in medieval skeletal samples from Croatia. Int. J. Paleopath. 7, 25-32. https://doi.org/10.1016/j.ijpp.2014.06.002

Okabe, A., Satoh, T., Sugihara, K., 2009. A kernel density estimation method for networks, its computational method and a GIS-based tool. Int. J Geogr. Inf. Sci. 23, 7-32. https://doi.org/10.1080/13658810802475491

Oxenham, M., Willis, A., Hung, H.C., Page, R., Matsumura, H., 2015. Dealing with death in late Neolithic to Metal Period Nagsabaran, the Philippines. In: Oxenham, M., Buckley, H. (Eds), The Routledge Handbook of Bioarchaeology in Southeast Asia and the Pacific Islands. Routledge, New York. pp. 339-366.

Oxenham, M.F., Tilley, L., Matsumura, H., Nguyen, L.C., Nguyen, K.T., Nguyen, K.D., Domett, K., Huffer, D., 2009. Paralysis and severe disability requiring intensive care in Neolithic Asia. Anthropol. Sci. 117, 107-12. https://doi.org/10.1537/ase.081114

Ou-Yang, H., Paschalis, E. P., Mayo, W. E., Boskey, A. L., Mendelsohn, R., 2001. Infrared microscopic imaging of bone: spatial distribution of CO32-. J. Bone Miner Res. 16, 893-900. https://doi.org/10.1359/jbmr.2001.16.5.893

Page, R. 2015. Iron Period Nagsabaran, Philippines: An Osteobiography of an Adult Male. Master Thesis. Australian National University, Canberra, Australia.

Paja, L., 2013. Joint Fusion in Paleopathology: Diagnosis and Epidemiology. PhD Thesis, University of Szeged/Ecole, Szeged, Hungary.

Piper, P.J., Hung, H-c., Campos, F.Z., Bellwood, P., Santiago, R. 2009. A 4000 year-old introduction of domestic pigs into the Philippine Archipelago: implications for 
understanding routes of human migration through Island Southeast Asia and Wallacea. Antiquity, 83, 687 - 695. https://doi.org/10.1017/S0003598X00098914

Pureepatpong, N., Sangiampongsa, A., Lerdpipatworakul, T., Sangvichien, S., 2012. Stature estimation of modern Thais from long bones: a cadaveric study. Siriraj Med. J., 64, 2225.

Reiche, I., Lebon, M., Chadefaux, C., Müller, K., Le Hô, A.S., Gensch, M., Schade, U., 2010. Microscale imaging of the preservation state of 5,000-year-old archaeological bones by synchrotron infrared microspectroscopy. Anal. Bioanal. Chem, 397, 2491-2499. https://doi.org/10.1007/s00216-010-3795-4

Resnick, D.L., Kransdorf, M.J., 2004. Bone and Joint Imaging. Elsevier Health Sciences, Philadelphia.

Rey, C., Collins, B., Goehl, T., Dickson, I.R., Glimcher, M.J., 1989. The carbonate environment in bone mineral: a resolution-enhanced Fourier transform infrared spectroscopy study. Calcif. Tiss. Int. 45, 157-164. https://doi.org/10.1007/BF02556059

Rider, C., 2017. Hip Joint Pathology and Lower Limb Skeletal Adaptation: A Case Study from the Metal Period Philippines. Master Thesis. Australian National University, Canberra, Australia.

Robling, A. G., Castillo, A. B., Turner, C. H., 2006. Biomechanical and molecular regulation of bone remodeling. Annu. Rev. Biomed. Eng., 8, 455-498. https://doi:10.1146/annurev.bioeng.8.061505.095721

Rogers. J, Waldron, T., 1995. A Field Guide to Joint Disease in Archaeology. John Wiley, New York. 
Rose, D. C., Agnew, A. M., Gocha, T. P., Stout, S. D., Field, J. S., 2012. The use of geographical information systems software for the spatial analysis of bone microstructure. Am. J. Phys. Anthropol. 148, 648-654.

Schlecht, S. H., Pinto, D. C., Agnew, A. M., Stout, S. D., 2012. Brief communication: the effects of disuse on the mechanical properties of bone: what unloading tells us about the adaptive nature of skeletal tissue. Amer. J. Phys. Anthropol. 149, 599-605. https://doi.org/10.1002/ajpa.22150

Sibonga, J. D., 2013. Spaceflight-induced bone loss: is there an osteoporosis risk? Curr. Osteoporos. Rep. 11, 92-98. https://doi.org/10.1007/s11914-013-0136-5

Uhthoff, H. K., Jaworski, Z. F., 1978. Bone loss in response to long-term immobilisation. J. Bone Jt. Surg. 60, 420-429. https://doi.org/10.1302/0301-620X.60B3.681422

Vidal, M., Thibodaux, R.J., Neira, L.F.V., Messina, O.D., 2019. Osteoporosis: a clinical and pharmacological update. Clin. Rheumatol. 38, 385-395. https://doi.org/10.1007/s10067-018-4370-1

Vongsvivut, J., Perez-Guaita, D., Wood, B.R., Heraud, P., Khambatta, K., Hartnell, D., Hackett, M., Tobin, M. J., 2019. Synchrotron macro ATR-FTIR microspectroscopy for high-resolution chemical mapping of single cells. Analyst, 144, 3161-3452. https://doi.org/10.1039/C8AN01543K

Vrahnas, C., Pearson, T.A., Brunt, A.R., Forwood, M.R., Bambery, K.R., Tobin, M.J., Martin, T.J., Sims, N.A. 2016. Anabolic action of parathyroid hormone (PTH) does not compromise bone matrix mineral composition or maturation. Bone, 93, 146-54. doi: 10.1016/j.bone.2016.09.022. 
Walker, M.M., Oxenham, M.F., Hiep, T.H., Nguyen, T.M.H., Miszkiewicz, J.J., 2019 (abstract) Preliminary descriptions of bone histology in an individual with a possible Klippel-Feil Syndrome, Type III from Neolithic Northern Vietnam. 33rd Australasian Society for Human Biology conference, Canberra, Australia. 
Table 1. Morphometric data for the right and left femur (all in mm).

\begin{tabular}{|l|c|c|}
\hline Gross anatomical measurements & Right femur & $\begin{array}{c}\text { Left femur } \\
\text { (ankylosed hip joint) }\end{array}$ \\
\hline Subtrochanteric antero-posterior diameter & 27.56 & 26.40 \\
\hline Subtrochanteric medio-lateral diameter & 36.13 & 36.89 \\
\hline Midshaft antero-posterior diameter & 24.24 & 24.44 \\
\hline Midshaft medio-lateral diameter & 24.64 & 23.99 \\
\hline Maximum head diameter & 46.23 & $\mathrm{n} / \mathrm{a}$ \\
\hline Midshaft circumference & 74.36 & 76.36 \\
\hline Maximum femoral neck diameter & 34.46 & 39.98 \\
\hline Posterior cortical width (gross measurement) & 8.55 & 7.91 \\
\hline Cortical width (histological measurement) & 7.50 & 7.40 \\
\hline
\end{tabular}


Table 2. Descriptive data from three methods quantifying cortical bone microstructure of each

left and right femur sample.

\begin{tabular}{|c|c|c|c|c|c|}
\hline Left femur (ankylosed hip joint) & $\mathbf{n}$ & Min. & Max. & Mean & SD \\
\hline $\begin{array}{l}\text { GIS*: Absolute distance between } \\
\text { neighbouring Haversian canals }(\mu \mathrm{m})\end{array}$ & 5349 & 31.000 & 510.000 & 160.582 & 58.052 \\
\hline $\begin{array}{l}\text { GIS: First nearest neighbour distance } \\
\text { between Haversian canals }(\mu \mathrm{m})\end{array}$ & 1783 & 31.000 & 417.000 & 123.800 & 46.851 \\
\hline HIS**: Haversian canal density & \multicolumn{5}{|c|}{$\left(1785 / 70.68 \mathrm{~mm}^{2}\right) 25.25$} \\
\hline HIS: Haversian canal area $\left(\mu \mathrm{m}^{2}\right)$ & 168 & 79.759 & $15,144.658$ & $1,906.401$ & $2,104.771$ \\
\hline $\begin{array}{l}\text { HIS: Haversian canal area/section area } \\
\left(/ 14.68 \mathrm{~mm}^{2}\right)\end{array}$ & 168 & 5.434 & $1,031.793$ & 129.881 & 143.396 \\
\hline HIS: Haversian canal circularity & 168 & 0.556 & 0.969 & 0.882 & 0.076 \\
\hline HIS: Haversian canal aspect ratio ${ }^{-1}$ & 168 & 0.330 & 0.981 & 0.720 & 0.151 \\
\hline sFTIRM $^{* * *}$ : phosphate peak height $(\mathrm{Au})$ & 2605 & 0.200 & 1.412 & 0.422 & 0.167 \\
\hline sFTIRM: phosphate area $(\mathrm{Au})$ & 2605 & 14.126 & 73.333 & 30.416 & 10.663 \\
\hline sFTIRM: Carbonate $v_{2}$ peak height $(\mathrm{Au})$ & 4894 & 0.001 & 0.076 & 0.019 & 0.014 \\
\hline sFTIRM: Carbonate $v_{2}$ area $(\mathrm{Au})$ & 4655 & 0.001 & 1.431 & 0.344 & 0.248 \\
\hline sFTIRM: Carbonate $v_{3}$ peak height $(\mathrm{Au})$ & 5170 & 0.001 & 0.053 & 0.013 & 0.008 \\
\hline sFTIRM: Carbonate $v_{3}$ area $(\mathrm{Au})$ & 4976 & 0.001 & 2.829 & 0.554 & 0.464 \\
\hline sFTIRM: Carbonate $v_{2}$ : phosphate ratio & 2601 & 0.001 & 0.036 & 0.016 & 0.003 \\
\hline \multicolumn{6}{|l|}{ Right femur } \\
\hline $\begin{array}{l}\text { GIS: Absolute distance between } \\
\text { neighbouring Haversian canals }(\mu \mathrm{m})\end{array}$ & 3567 & 42.000 & 560.000 & 200.089 & 61.839 \\
\hline $\begin{array}{l}\text { GIS: First nearest neighbour distance } \\
\text { between Haversian canals }(\mu \mathrm{m})\end{array}$ & 1189 & 42.000 & 343.000 & 155.480 & 50.547 \\
\hline HIS: Haversian canal density & \multicolumn{5}{|c|}{$\frac{1}{\left(1192 / 68.65 \mathrm{~mm}^{2}\right) 17.36}$} \\
\hline HIS: Haversian canal area $\left(\mu \mathrm{m}^{2}\right)$ & 145 & 230.598 & $17,984.935$ & $2,567.975$ & $2,564.642$ \\
\hline $\begin{array}{l}\text { HIS: Haversian canal area/ section area } \\
\left(/ 12.92 \mathrm{~mm}^{2}\right)\end{array}$ & 145 & 17.853 & $1,392.400$ & 198.817 & 198.559 \\
\hline HIS: Haversian canal circularity & 145 & 0.490 & 0.964 & 0.872 & 0.093 \\
\hline HIS: Haversian canal aspect ratio ${ }^{-1}$ & 145 & 0.219 & 0.995 & 0.692 & 0.167 \\
\hline sFTIRM: phosphate peak height $(\mathrm{Au})$ & 3893 & 0.201 & 0.963 & 0.441 & 0.149 \\
\hline sFTIRM: phosphate area $(\mathrm{Au})$ & 3893 & 14.453 & 63.984 & 30.660 & 9.050 \\
\hline sFTIRM: Carbonate $v_{2}$ peak height $(\mathrm{Au})$ & 5182 & 0.001 & 0.092 & 0.026 & 0.013 \\
\hline sFTIRM: Carbonate $v_{2}$ area $(\mathrm{Au})$ & 5128 & 0.002 & 1.598 & 0.439 & 0.233 \\
\hline sFTIRM: Carbonate $v_{3}$ peak height $(\mathrm{Au})$ & 5112 & 0.001 & 0.055 & 0.017 & 0.008 \\
\hline sFTIRM: Carbonate $v_{3}$ area $(\mathrm{Au})$ & 5048 & 0.003 & 2.932 & 0.778 & 0.451 \\
\hline sFTIRM: Carbonate $v_{2}$ : phosphate ratio & 3882 & 0.001 & 0.031 & 0.017 & 0.003 \\
\hline
\end{tabular}

* Geographic Information Systems (GIS) mapping Haversian canal dispersal to estimate clustering throughout the sample

** static histomorphometry (HIS) measuring Haversian canal area (in $\left.\mu \mathrm{m}^{2}\right)$, circularity and inverted aspect ratio, and density

*** synchrotron-sourced Fourier-transform infrared (sFTIRM) microspectroscopy indicative of phosphate, carbonate $\left(v_{3}, v_{2}\right)$, and carbonate:phosphate ratios 


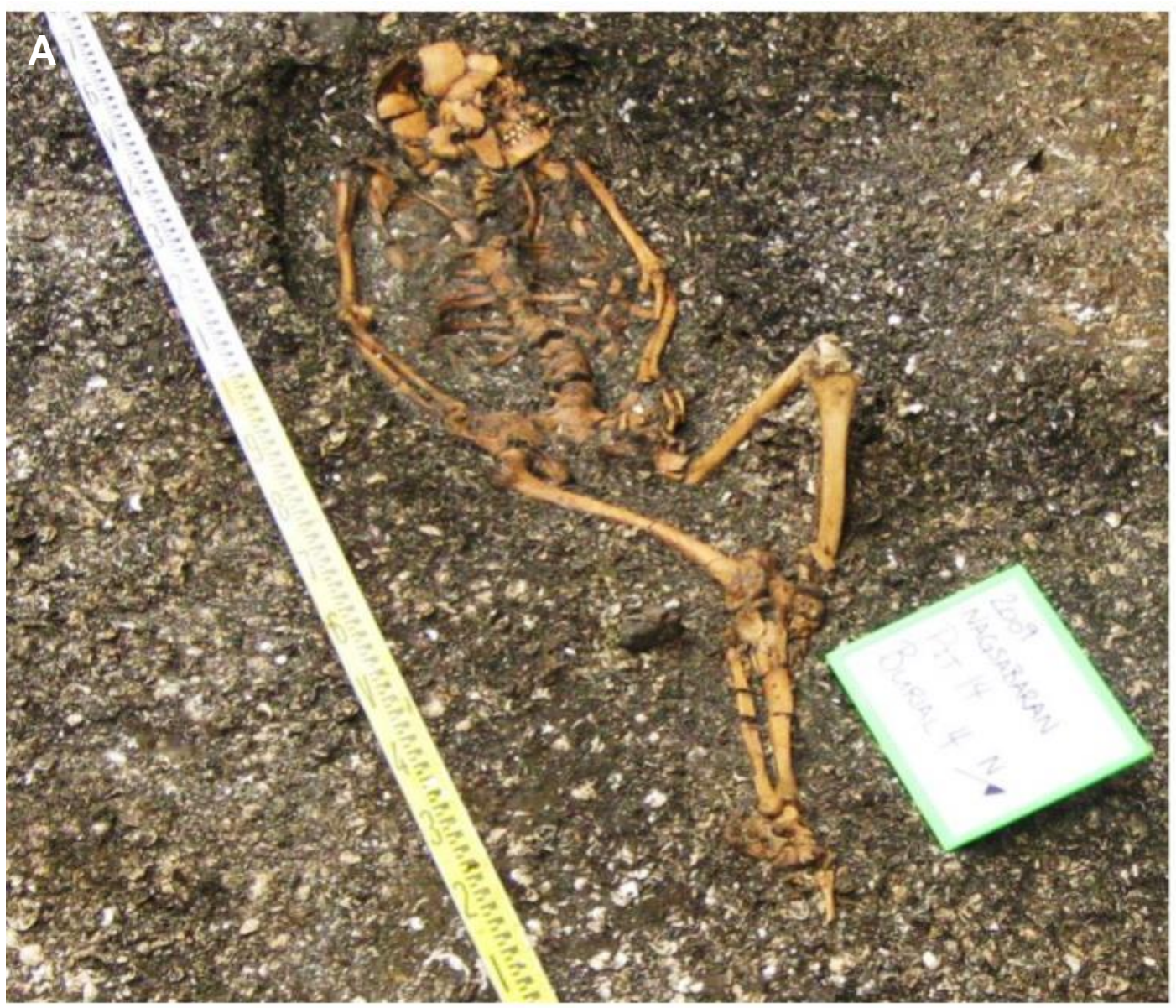

\section{B}
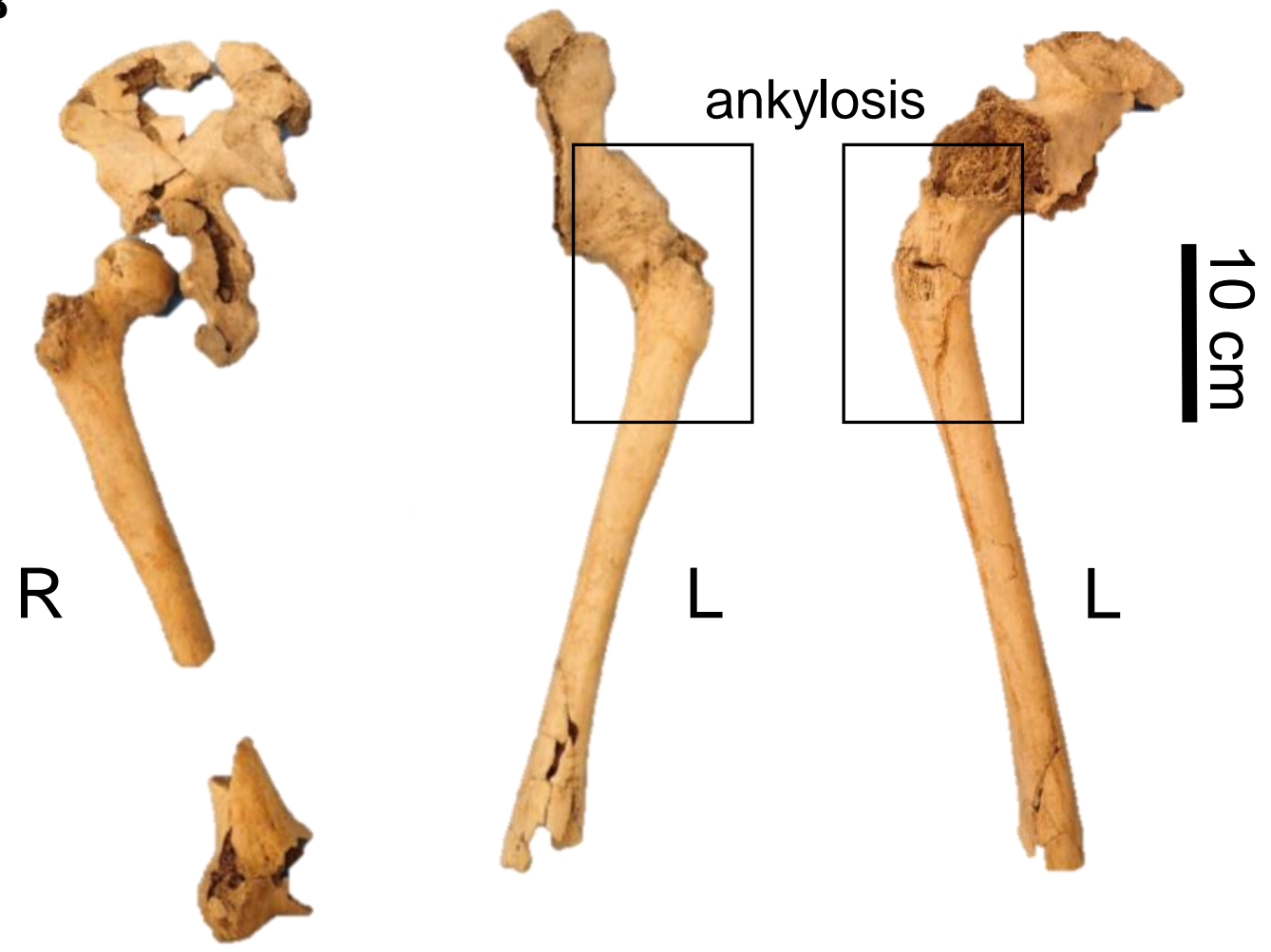

Anterior

Posterior 
$\mathbf{A}$ FROM ANKYLOSED HIP JOINT
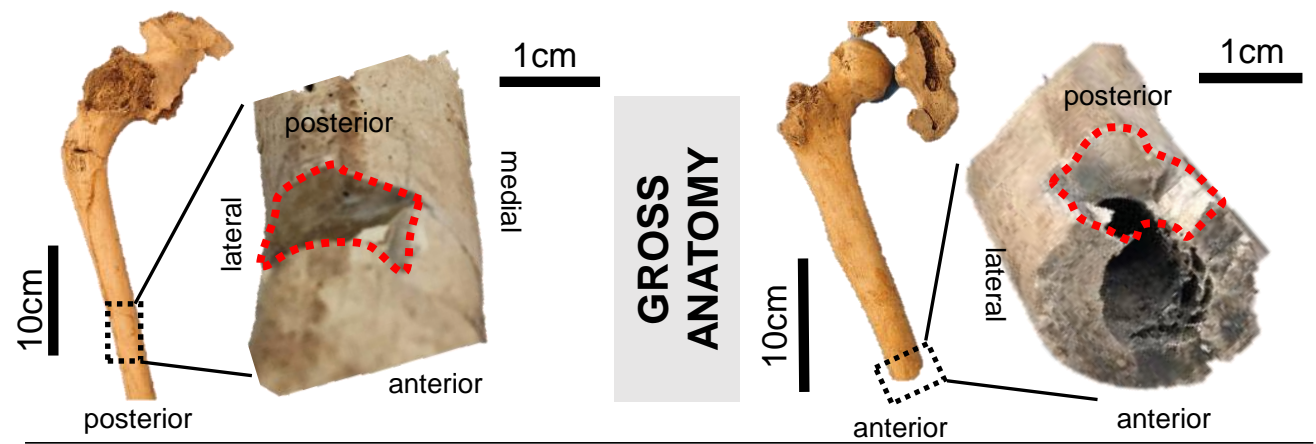

B
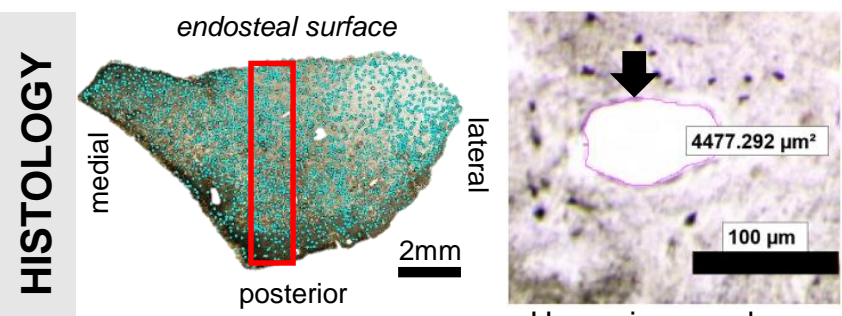

Haversian canal area
RIGHT FEMUR NO HIP ANKYLOSIS

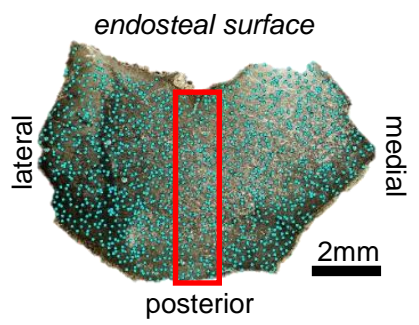

C

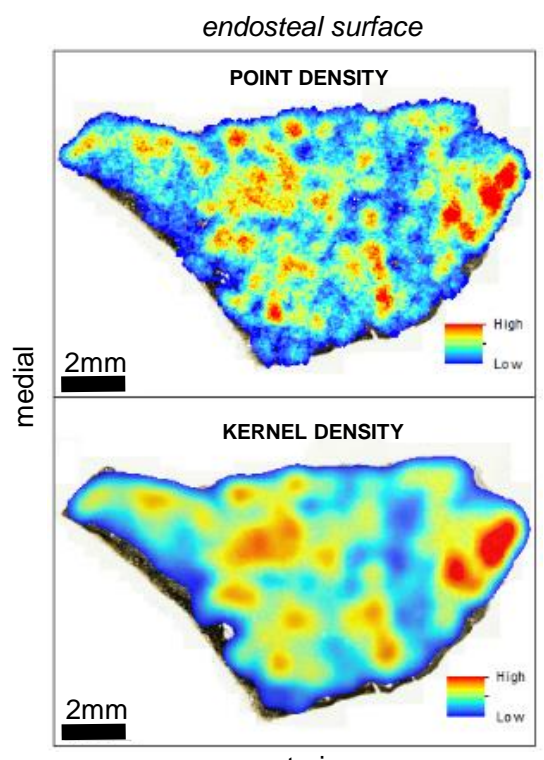

posterior

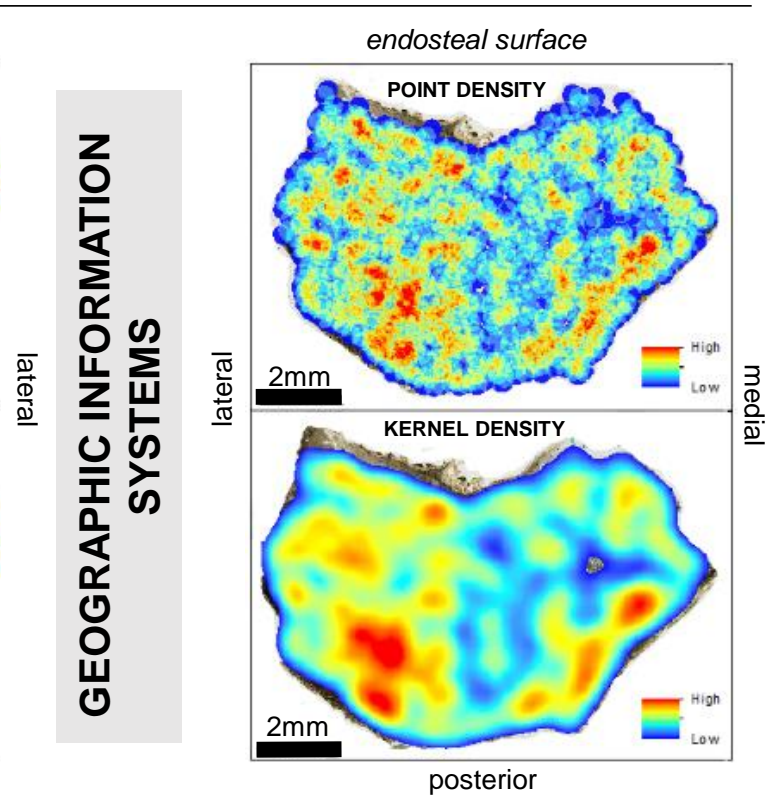

D
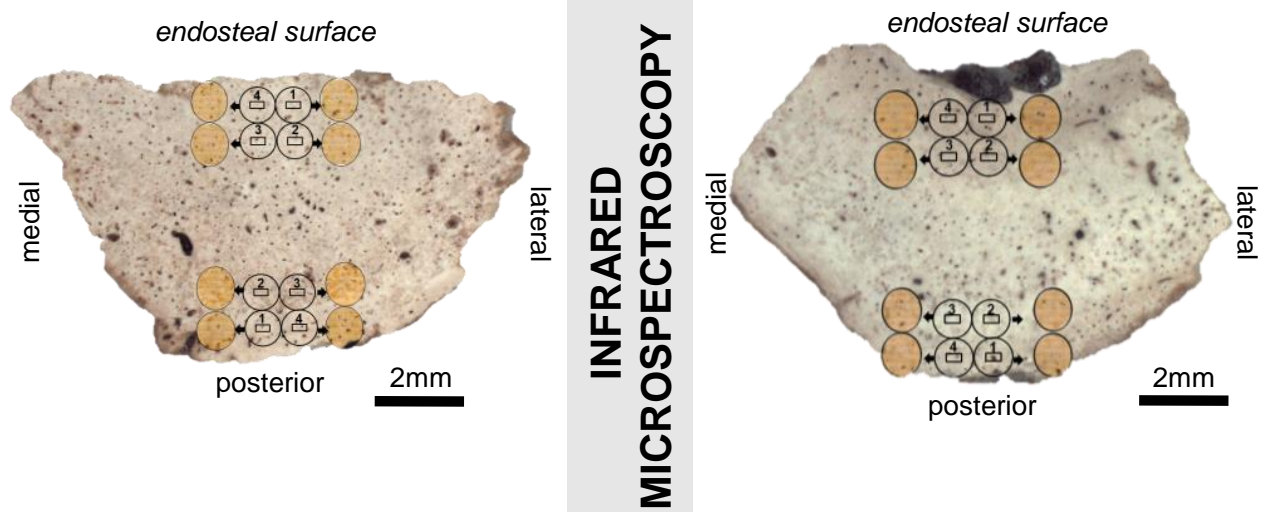
ANALYSIS OF HAVERSIAN CANALS

Canal area

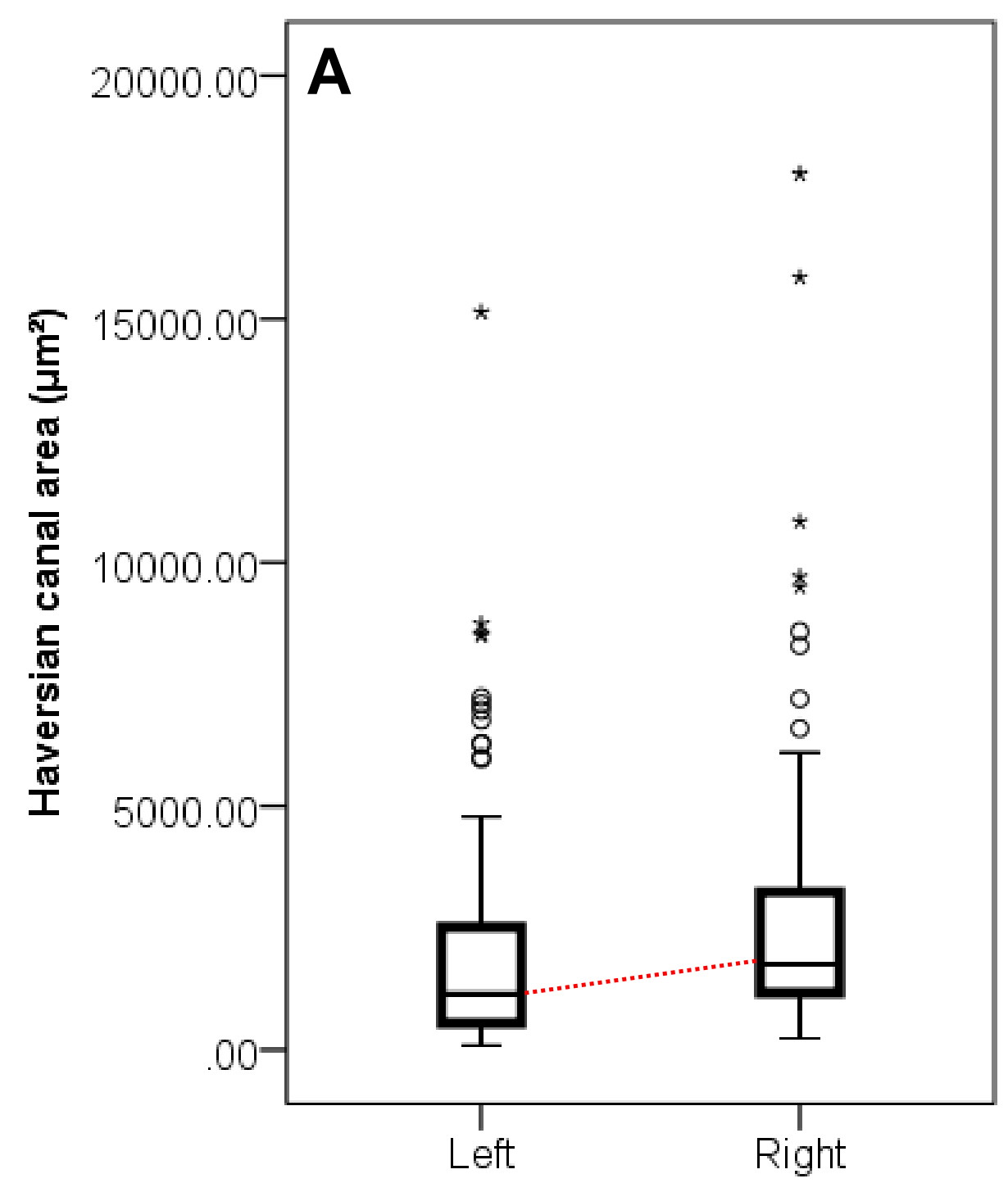

Femur side

Canal circularity

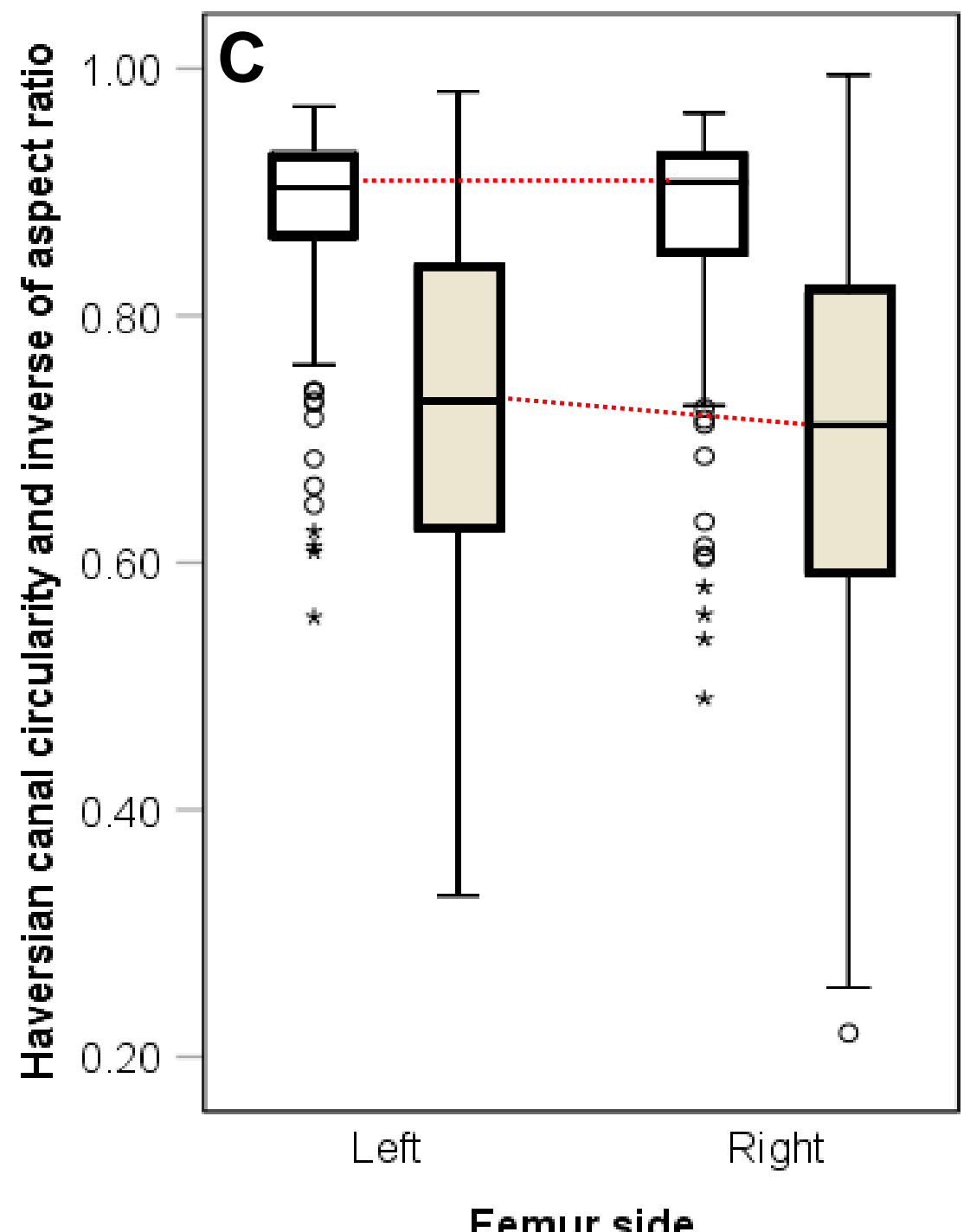

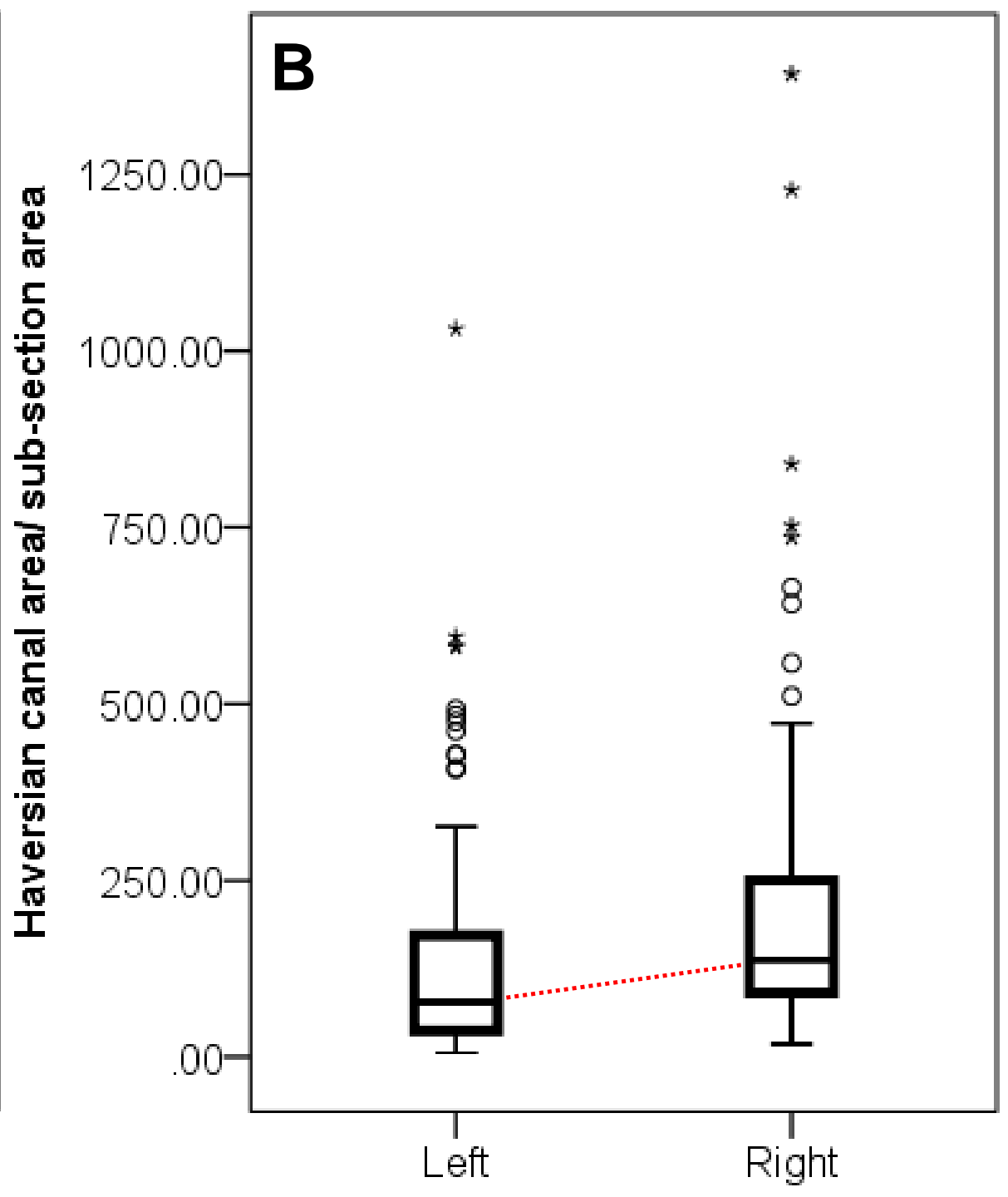

Femur side

Canal dispersal (GIS)

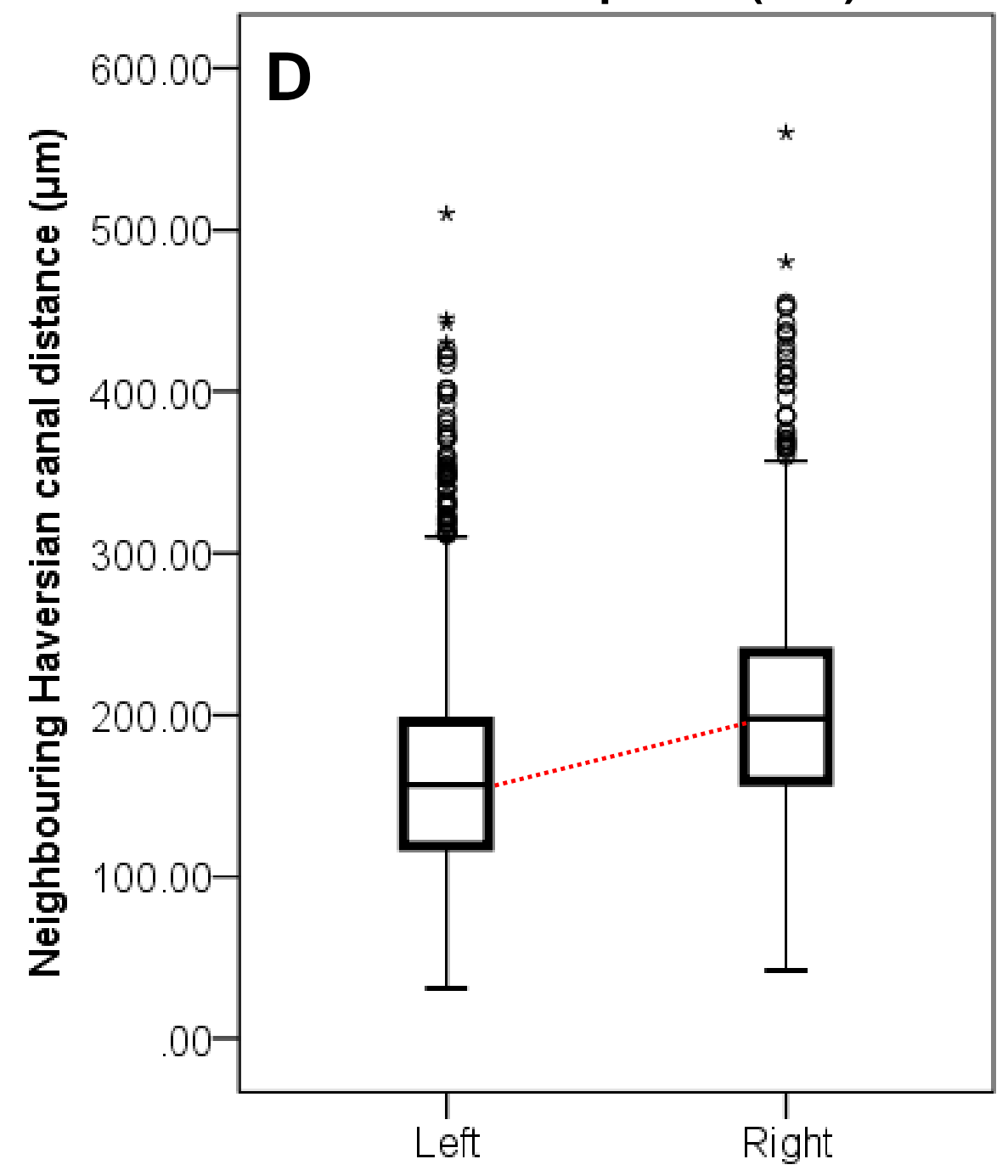

Femur side 
SYNCHROTRON SOURCE INFRARED MICROSPECTROSCOPY RESULTS

CARBONATE AND PHOSPHATE
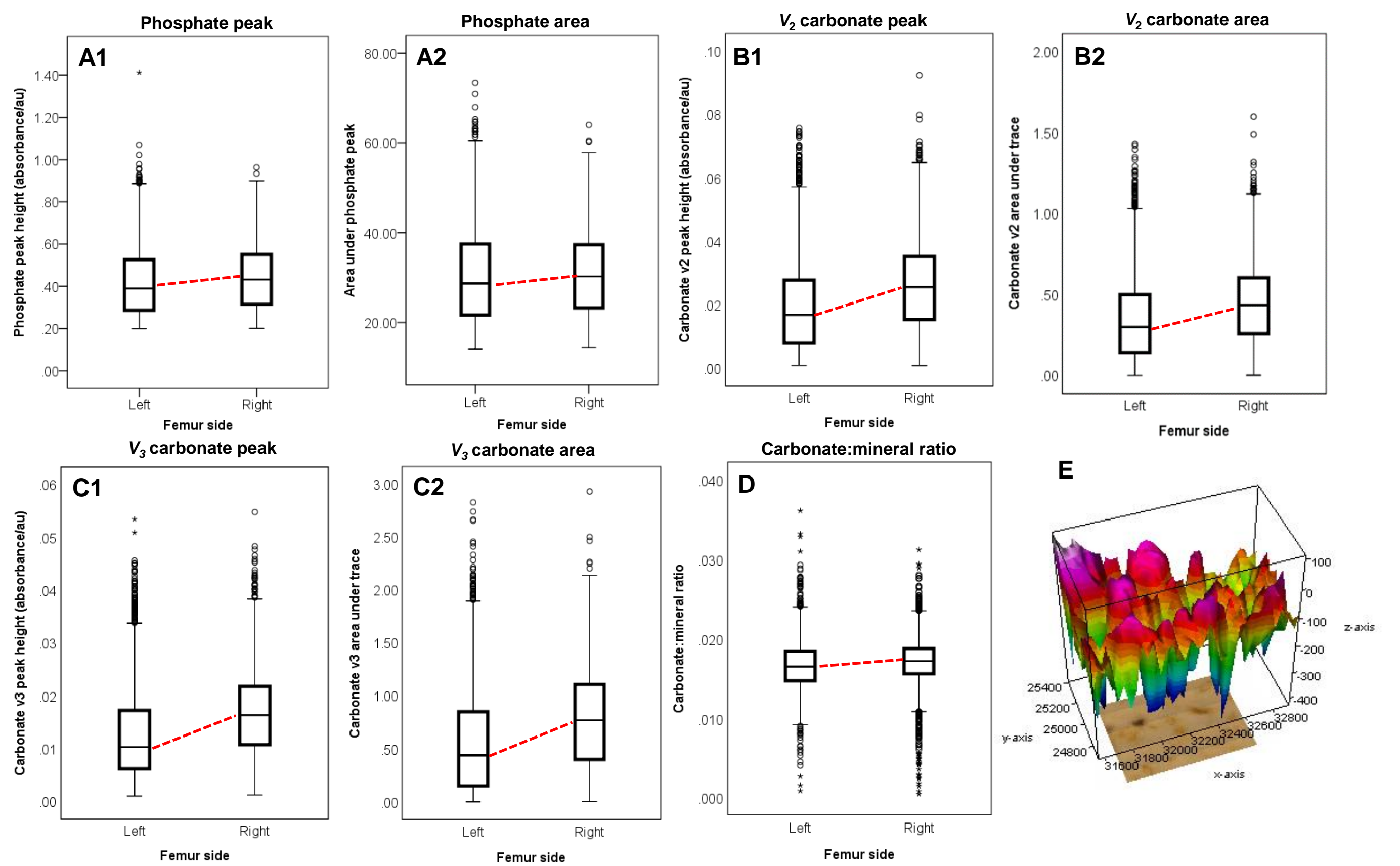
EXAMPLE AVERAGED SPECTRA FROM

ONE ENDOCORTICAL REGION OF INTEREST

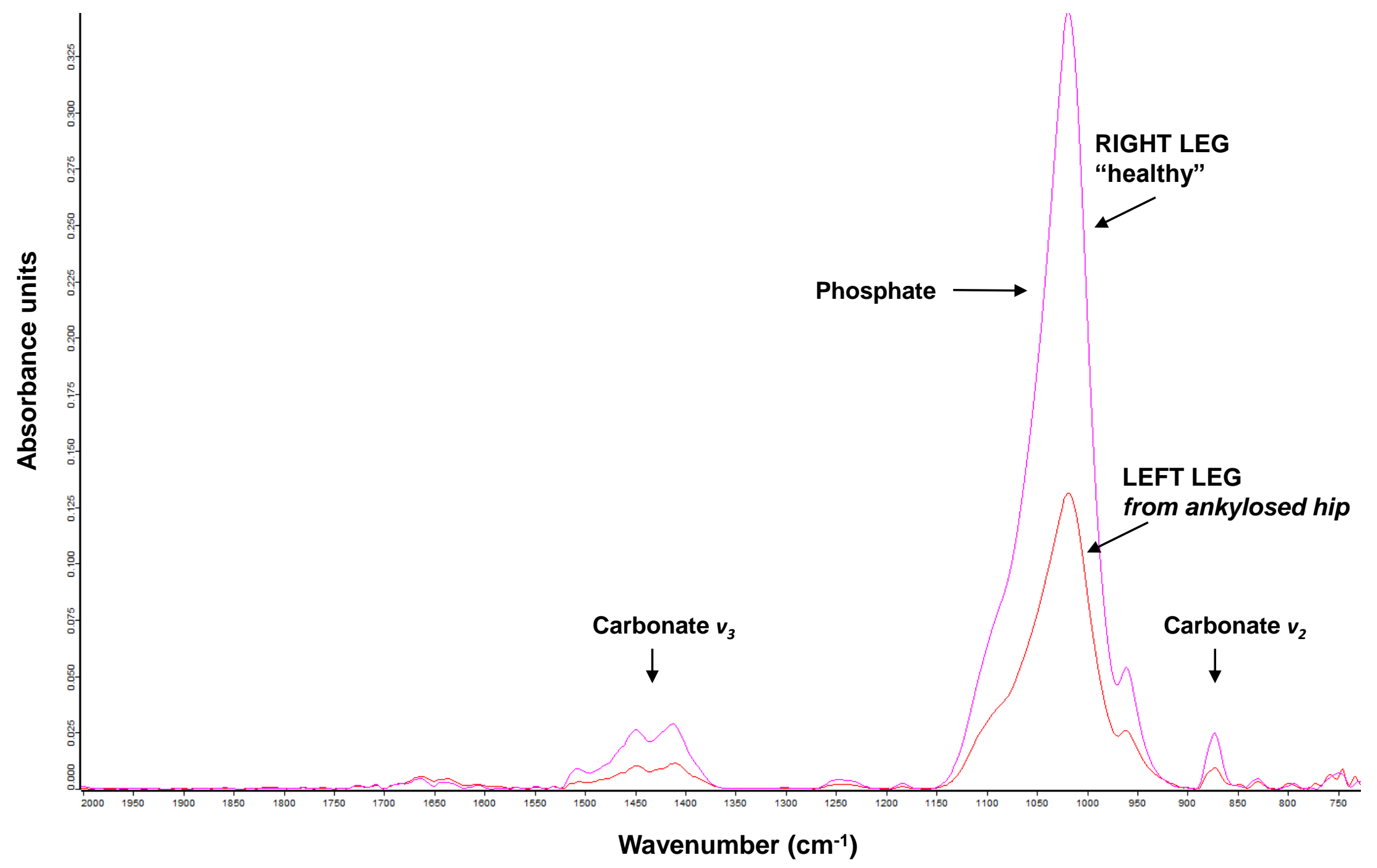




\section{SUPPLEMENT 1}

\section{Background - bone health and leg disuse in modern contexts}

Bone is a dynamic tissue that is constantly broken down and replaced through stochastic remodeling (Parfitt, 1994). It adapts and re-distributes in response to varying mechanical loads, which has been extensively described under the Utah Paradigm of Skeletal Biology (Jee, 2005) and a principle known as the Mechanostat (Frost, 1987; Pivonka et al., 2017). The Mechanostat stipulates a strain threshold (setpoint) that governs bone remodeling or modeling responses to load via a minimum effective strain (MES) (Frost, 1983). The MES is quantified in strain per bone unit (microstrains) and it determines what type of bone activity (remodeling or modeling) will be evoked in response to load when the thresholds are crossed (Frost, 1992). Classic histological and radiographic data have shown that continuous abnormally low microstrains can cause limb bone cortex to abandon modeling (in actively growing bones), increasing endocortical resorption that eventually result in thin cortices and bone loss (Jawroski et al., 1980; Young et al., 1986). For example, Young et al. (1986) restrained the hind-limbs of Southern pig-tailed macaques (Macaca nemestrina) to show suppressed osteoblast function and uninterrupted cortical bone resorption occurring within a period of up to 7 months of immobilization. Jaworski et al.’s (1980) experiments on Beagle dogs (Canis lupus familiaris) reported cortical bone loss in cast-restricted forelimbs within 7.5 months (32 weeks) of inactivity. Within the first two months of immobilization the forelimb exhibited cortical bone mass reduction by $5-10 \%$ against the control, with a subsequent phase of increased cortical bone loss at three months (Jaworski et al., 1980). Therefore, we can expect increased bone remodeling (with enhanced osteoclast activity) very shortly after an event of mechanical disuse.

In modern humans, bone health data for astronauts on long-term space missions show detrimental effects of suspension in a weightless environment: "Indeed, astronauts typically 
lose more bone mass during one month than postmenopausal women on Earth lose in one year." (Cappellesso et al., 2015:231). For example, a 2015 study by Sibonga et al. analysed wholebone mineral density (BMD) in $\mathrm{n}=68$ International Space Station (ISS) astronauts and crewmembers at the NASA Johnson Space Center to report declining BMD across pelvic and spine sites. A sub-sample of $\mathrm{n}=26$ ISS crewmembers in that study, who had not used exercise equipment while on mission, experienced a reduction in BMD that ranged from $-3.7 \%(\mathrm{SD}=$ $3.5)$ in the lumbar spine to $-6.6 \%(\mathrm{SD}=4.4)$ in the pelvis (Sibonga et al., 2015: A42). These data were almost double of BMD \% change in ISS crewmembers, who had exercised while on mission (e.g. $-2.8 \%, \mathrm{SD}=4.1$ in the pelvis). Sibonaga et al. (2015) concluded that a standard 6-month long space mission can lead astronauts and cosmonauts to be classified as an "at risk" population susceptible to fractures due to increased bone fragility. On the ground, Schlecht et al. (2012) compared upper and lower limb bones in two quadriplegic females with a control group of 28 fully mobile individuals (males and females). Using multiple complementary techniques, including cortical bone histology to extrapolate about remodeling based on secondary osteon density and cross-sectional geometric properties, Schlecht et al. (2012) demonstrated that bones from quadriplegic patients had lower osteon population densities and increased endocortical resorption.

\section{Methods - further details}

a) Entheseal assessment - we note that no detailed entheseal assessment was attempted due to increasing evidence for a lack of direct relationship between entheseal surfaces and underlying bone remodeling (Miszkiewicz et al., 2014; Rabey et al., 2015; Djukic et al., 2015).

b) Histology preparation - samples were embedded in Buehler® epoxy resin, mounted on a Kemet MICRACUT ${ }^{\circledR}$ precision cutter vise and cut in a transverse plane using a $150 \mathrm{~mm}$ diamond wheel. One $150 \mu \mathrm{m}$ thin slice was removed from the left and right 
sample and designated for the sFTIRM analysis. The remainder of each embedded sample was cut in half to reveal cortical surfaces for histological imaging. The exposed surface was glued to a microscope slide using Stuk ${ }^{\circledR}$ epoxy glue. Following subsequent reduction on a precision cutter, the sample was lapped on a series of silicon carbide pads (coarse to fine grit size). Approximately $100 \mu \mathrm{m}$ thin sections were then polished using Buehler ${ }^{\circledR}$ MicroPolish alumina powder, cleaned in an ultrasonic bath, dehydrated in ethanol baths, cleared in xylene, and cover-slipped. Examination and recording of images was done using an AmScope MU130 and a high powered Olympus BX53 microscope with a DP74 camera. Overview images were created using automated stitching tools of the AmScope 3.2 and Olympus CellSens ${ }^{\circledR}$ Life Science Technology software under total magnification of 100x.

c) Histomorphometric variables - Haversian canals of secondary osteons were easily identifiable (Figure 2B), while cement lines were inconsistently preserved throughout the cortical microstructure. Therefore, the histomorphometric analysis focused on counting Haversian canals (cortical pores) and estimating their density (H.Dn) by dividing the total count of canals by sample area. In addition to Haversian canals, osteocyte lacunae and Volkmann's canals (radial canals that connect Haversian canals transversely) are also considered histological cavities as bone is naturally porous (Wang and $\mathrm{Ni}, 2003)$. These were excluded from our study, as the number and size of Haversian canals can be considered good indicators of remodeling activity of a cutting cone during bone multicellular-unit (BMU) activity (Lassen et al., 2017). To that end, we also measured the area (H.Ar; Miszkiewicz and Mahoney, 2019), circularity (H.Cr) and inverted aspect ratios (H.AspR ${ }^{-1}$ ) of Haversian canals (Hennig et al., 2015; Maggio and Franklin, 2019). This will provide an insight into the extent of tunnel refilling by the BMUs. Circularity was considered a perfect circle when the index $=1$, with values 
$<1$ suggesting more irregular shapes [Cr $=4 \pi\left(\right.$ area/perimeter $\left.{ }^{2}\right)$; Keenan et al., 2017].

The H.AspR ${ }^{-1}$ values were obtained following Hennig et al (2015) methods. Raw Aspect Ratio (AR = major axis/ minor axis) data computed by Image ${ }^{\circledR}$ (v. 1.52) were inverted to obtain a value from 0 to 1 . Data closer to 0 indicate "infinitely elongated" pores, whereas values closer to 1 indicate "perfectly circular" pores (Hennig et al., 2015: 500). Because circularity relies on a perimeter measurement, adding H.AspR ${ }^{-1}$ data supplements it with an elongation measure based on the maximum and minimum axis.

d) The "Polygon" selection was used to measure section area in $\mathrm{mm}^{2}$, whereas the "Straight line" provided a maximum cortical (2D) width from the endosteal to periosteal borders (Miszkiewicz and Mahoney, 2016; 2019). Haversian canals were counted using the "Multi-Point" tool. The "Freehand" tool was used to collect H.Ar data in $\mu \mathrm{m}^{2}$, and H.Cr and AR data (unitless), by tracing the border of each canal within a cortical strip (encompassing the endosteal, intra-cortical, and periosteal areas of bone) measuring $14.678 \mathrm{~mm}^{2}$ (left femur) and $12.916 \mathrm{~mm}^{2}$ (right femur). The strip was composed by implementing an Image ${ }^{\circledR}$ (v. 1.52) mid-section grid of multiple $1 \mathrm{~mm}^{2}$ squares. We report raw H.Ar data as well as data adjusted by the sampled area to avoid possible isometry of section size and Haversian area (Miszkiewicz and Mahoney, 2019). Only fully completed ('intact') Haversian canals were measured and counted so that only osteons that had completed forming were included in our analysis. Using the Image ${ }^{\circledR}$ (v. 1.52) "Magnifying glass" tool, each pore was zoomed in to between $1200 \%-1600 \%$ to magnify its border to a pixel level. Using a mouse cursor, we then manually traced the border of the canal.

e) Synchrotron scanning - The IRM beamline facilitates an in situ analysis of mineral composition in the samples through a focused infrared beam that is provided by the 
synchrotron light source. The ROIs were then identified and marked on the overview image so that they were located on the midline of the sample with four ROIs immediately next to each other on the endocortical and sub-periosteal surfaces. Although within each ROI, a total of 665 spectra was collected (totalling 5,320 spectra for each femur), the uneven surface of the sample meant that full contact between the ATR attachment and bone surface was not successful across the entire surface. Subsequent data cleaning, to remove phosphate peak height values $<0.2$, and carbonate and phosphate area values in the negative range to 0.001 indicating lack of contact, reduced the data set to minimum 2,605 and maximum 5,170 spectra in the left, and 3,893 minimum and 5,128 maximum spectra in the right femur. Overview images of the samples were first created at $2 \mathrm{x}$ magnification using a simple dissecting microscope

(Figure 2D). These are relevant to our research question because bone functional capabilities are tied to its crystal structure which is influenced by carbonate substitution in mineral (Madupalli et al., 2017).

\section{REFERENCES CITED}

Cappellesso, R., Nicole, L., Guido, A., Pizzol, D., 2015. Spaceflight osteoporosis: current state and future perspective. Endocr. Regul. 49, 231-239. https://doi:10.4149/endo_2015_04_231

Djukic, K., Milovanovic, P., Hahn, M., Busse, B., Amling, M., Djuric, M., 2015. Bone microarchitecture at muscle attachment sites: the relationship between macroscopic scores of entheses and their cortical and trabecular microstructural design. Am. J. Phys. Anthropol. 157, 81-93. https://doi:10.1002/ajpa.22691.

Frost, H. M., 1983. A determinant of bone architecture. The minimum effective strain. Clin. Orthop. Relat. Res. 175, 286-292.

Frost, H. M., 1987. Bone "mass" and the "mechanostat": a proposal. Anat. Rec. 219, 1-9. https://doi: 10.1002/ar.1092190104

Frost, H. M., 1992. Perspectives: the role of changes in mechanical usage set points in the pathogenesis of osteoporosis. J. Bone Miner. Res. 7, 253-261.

https://doi.org/10.1002/jbmr.5650070303 
Hennig, C., Thomas, C. D. L., Clement, J. G., Cooper, D. M., 2015. Does 3D orientation account for variation in osteon morphology assessed by 2D histology?. J. Anat. 227(4), 497-505.

Jaworski, Z. F., Liskova-Kiar, M., Uhthoff, H. K., 1980. Effect of long-term immobilisation on the pattern of bone loss in older dogs. J. Bone Jt. Surg. 62, 104-110.

Jee, W. S., 2005. HM Frost's legacy: The Utah paradigm of skeletal physiology. Niigata J. Health Welf. 6, 1-9.

Keenan, K.E., Mears, C.S., Skedros, J.G., 2017. Utility of osteon circularity for determining species and interpreting load history in primates and nonprimates. Am. J. Phys. Anthropol. 162, 657-681. https://doi.org/10.1002/ajpa.23154

Lassen, N.E., Andersen, T.L., Pløen, G.G., Søe, K., Hauge, E.M., Harving, S., Eschen, G.E., Delaisse, J.M., 2017. Coupling of bone resorption and formation in real time: new knowledge gained from human Haversian BMUs. J. Bone Miner. Res. 32, 1395-405. https://doi.org/10.1002/jbmr.3091

Madupalli, H., Pavan, B., Tecklenburg, M.M., 2017. Carbonate substitution in the mineral component of bone: Discriminating the structural changes, simultaneously imposed by carbonate in A and B sites of apatite. J. Solid State Chem. 255, 27-35. https://doi.org/10.1016/j.jssc.2017.07.025

Maggio, A., Franklin, D., 2019. Histomorphometric age estimation from the femoral cortex: A test of three methods in an Australian population. Forensic Sci. Int. 303, 109950. https://doi.org/10.1016/j.forsciint.2019.109950

Miszkiewicz, J.J., Kivell, T.L., Schlecht, S.H., Mahoney, P., 2015. Investigating the extent to which entheseal changes reflect bone remodeling at the modern human femoral midshaft. Am. J. Phys. Anthropol. 156, 227-227. doi:10.1002/ajpa.22718.

Miszkiewicz, J. J., Mahoney, P., 2016. Ancient human bone microstructure in medieval England: comparisons between two socio-economic groups. Anat. Rec. 299, 42-59. https://doi.org/10.1002/ar.23285

Miszkiewicz, J. J., Mahoney, P., 2019. Histomorphometry and cortical robusticity of the adult human femur. J. Bone Miner. Metab. 37(1), 90-104. https://doi: 10.1007/s00774-0170899-3.

Parfitt, A. M. 1994. Osteonal and hemi-osteonal remodeling - the spatial and temporal framework for signal traffic in adult human bone. J. Cell. Biochem. 55, 273-286 https://doi.org/10.1002/jcb.240550303

Pivonka, P., Park, A., Forwood, M. R., 2018. Functional adaptation of bone: The Mechanostat and beyond. In: Pivonka, P. (Ed), Multiscale Mechanobiology of Bone Remodeling and Adaptation. Springer, Cham, pp. 1-60. https://doi.org/10.1007/978-3-319-58845-2_1

Rabey, K. N., Green, D. J., Taylor, A. B., Begun, D. R., Richmond, B. G., McFarlin, S. C., 2015. Locomotor activity influences muscle architecture and bone growth but not muscle attachment site morphology. J. Hum. Evol., 78, 91-102. https://doi.org/10.1016/j.jhevol.2014.10.010

Schlecht, S. H., Pinto, D. C., Agnew, A. M., Stout, S. D., 2012. Brief communication: the effects of disuse on the mechanical properties of bone: what unloading tells us about 
the adaptive nature of skeletal tissue. Amer. J. Phys. Anthropol. 149, 599-605. https://doi.org/10.1002/ajpa.22150

Sibonga, J. D., 2013. Spaceflight-induced bone loss: is there an osteoporosis risk? Curr. Osteoporos. Rep. 11, 92-98. https://doi.org/10.1007/s11914-013-0136-5

Sibonga, J. D., Spector, E. R., Johnston, S. L., Tarver, W. J., 2015. Evaluating bone loss in ISS astronauts. Aerosp. Med. Hum. Perf. 86, A38-A44. https://doi.org/10.3357/AMHP.EC06.2015

Wang, X., Ni, Q., 2003. Determination of cortical bone porosity and pore size distribution using a low field pulsed NMR approach. J. Orthop. Res., 21, 312-319. https://doi.10.1016/S0736-0266(02)00157-2

Young, D. R., Niklowitz, W. J., Brown, R. J., Jee, W. S. S., 1986. Immobilization-associated osteoporosis in primates. Bone, 7, 109-117. https://doi.org/10.1016/87563282(86)90682-4 